\title{
SISTEMA SOCIOEDUCATIVO: UMA ANÁLISE SOBRE AS CONCEPÇÕES DE EDUCAÇÃO DO SISTEMA DE GARANTIA DE DIREITOS DO RIO DE JANEIRO*
}

\author{
Vivian de Oliveira ${ }^{1}$
}

Ao longo das últimas décadas, podemos perceber uma tentativa de reconhecimento da criança e do adolescente como sujeitos participantes da sociedade brasileira, principalmente quando são concebidas concepções que reconhecem características peculiares e únicas deste público, diferenciando-os de outros momentos da vida humana.

Com o advento da Doutrina da Proteção Integral ${ }^{2}$, estes ganham assim, status de cidadãos, conforme estabelece o artigo 227 da Constituição Federal, e regulamentado pelo Estatuto da Criança e do Adolescente - ECA (Lei 8.069 de 13 de julho de 1990), considerado um marco nacional para o desenvolvimento de políticas públicas de atenção a infância e adolescência.

Neste contexto garantista, a política socioeducativa ${ }^{3}$ representa seguramente uma conquista no que diz respeito aos marcos normativos voltados a defesa e promoção de direitos de adolescentes e jovens que cumprem as medidas socioeducativas $^{4}$. Seu componente específico e peculiar, visto corresponder ao conjunto de ações que são realizadas no âmbito do poder público a partir da ocorrência de um acontecimento delituoso que teve o adolescente como protagonista, a torna um importante instrumento de defesa para este público, pois reconhece que as medidas aplicadas têm incidência, duração e lugar limitados,

\footnotetext{
${ }^{*}$ DOI - 10.29388/978-65-86678-41-3-0-f.213-228

${ }^{1}$ Pedagoga, Mestra em educação pela Universidade Federal Fluminense. Técnica em Assuntos Educacionais da Universidade Federal do Rio de Janeiro.

${ }^{2}$ Doutrina jurídica contrária a Situação Irregular que consiste, a luz do ECA, em garantir legalmente todas as condições para que cada criança e adolescente brasileiro tenha assegurado seu pleno desenvolvimento físico, moral e espiritual (COSTA, 2006, p. 152).

${ }^{3}$ Nomenclatura utilizada a partir da Lei 8.069/90 - Estatuto da Criança e Adolescente (ECA) para designar o cumprimento de medidas aplicáveis a adolescentes e jovens que praticam atos infracionais análogos ao Código Penal.

${ }^{4}$ As medidas socioeducativas de internação e semiliberdade são executadas pelos estados da federação. As medidas de meio aberto e prestação de serviço à comunidade são de responsabilidade dos municípios.
} 
não se estendendo a todo adolescente, nem tampouco por toda esta fase da vida.

O panorama legal do sistema brasileiro aponta para um aprimoramento quando fundamentado nos pressupostos da Doutrina da Proteção Integral ao estabelecer em suas diretrizes, que as medidas socioeducativas são além de responsabilizadoras, em razão de sua natureza sancionatória, devem ter seu conteúdo socioeducativo, ou seja, requer a predominância de ações educativas sobre os aspectos punitivos.

Por esta concepção, a educação é considerada então parte estruturante de toda ação socioeducativa, e neste sentido, temos a hipótese de que o sucesso das medidas aplicadas aos adolescentes que cometeram ato infracional depende de uma política socioeducativa articulada, consolidada em ações educativas que criem acontecimentos estruturantes ao adolescente, o que vai muito além de uma discussão de natureza jurídica sobre a punição pelo ato infracional cometido. Não mais sendo considerada um privilégio, benefício ou troca, mais um direito a ser consolidado que signifique a este adolescente o resgate de sua dignidade como ser humano e sua autoestima para seu retorno ao convívio social.

Nesta perspectiva, a política socioeducativa contemporânea, fundamentada nestes pressupostos, requer então de todos os atores que a compõem, que esforços sejam empreendidos de modo que os fins da socioeducação - educação para o convívio social (COSTA, 2006) - sejam consolidados, reconhecendo que o desenvolvimento do ser humano deve se dar de forma integral, contemplando todas as dimensões do ser, e que sejam inerentes ao desenvolvimento do sujeito frente aos desafios da vida em liberdade.

Em se tratando desta Política se configurar em um Sistema com um modelo de atendimento integrado e articulado, a atuação convergente e intercomplementar dos atores institucionais - Sistema de Garantia de Direitos $\mathrm{SGD}^{5}$ (Sistema de Administração da Justiça Juvenil, Instâncias públicas e Sociedade Civil) envolvidos em seu desenvolvimento, se configura em uma premissa básica para as efetivas respostas pedagógicas desta política considerada garantista.

Não se pretende aqui discutir questões como os fatos sociais que levaram tais sujeitos ao cometimento do ato infracional, nem tampouco absolvições, pois o ECA ressalta seus deveres e as sanções para seus desvios. Pretende-se aqui promover reflexões sobre a política Socioeducativa tendo como fundamento suas bases éticas e pedagógicas, onde se espera que não mais haja

5 Segundo Wanderlino Nogueira Neto (1996), é um Sistema estratégico jurídico-políticoinstitucional para garantir direitos da infância e adolescência. 
espaço para a subsistência do modelo de atendimento centralizado, vertical, assistencialista e correcional/repressivo, que vigorou sob a égide da Doutrina da Situação Irregular ${ }^{6}$, que além da judicialização das questões sociais, marcava nitidamente a criminalização da pobreza, refletindo, assim, a ascendência do poder estatal sobre as causas da infância e juventudes pobres.

Partindo destas considerações, surgem os questionamentos que originaram este trabalho: é possível perceber os avanços conquistados no plano legal no cotidiano de atendimento, ou se configuram grandes paradoxos frente ao paradigma contemporâneo? A Política Socioeducativa atual é compreendida por todos os envolvidos e como de fato compreendem o significado da ação educativa neste atendimento, assim como seu papel dentro desta política? Como os agentes operadores do Sistema de Garantia de Direitos - SGD do es tado do Rio de Janeiro, responsáveis pela deliberação, gestão, execução, controle e fiscalização, compreendem a política socioeducativa, principalmente levando-se em consideração o parâmetro da natureza pedagógica das medidas e o caráter sancionatório educativo que, segundo a legislação vigente, deve permear todo atendimento? Sua formulação é pensada e executada a partir dos fins propostos para uma ação socioeducativa transformadora, ou seja, que permita aos adolescentes vivenciarem novas oportunidades que lhes confiram possibilidades de construírem novas competências pessoais e relacionais para suas vidas, assim como seu convívio social? O que pensam sobre a Educação na Socioeducação? Ela tem tido papel relevante nesta política?

Uma das hipóteses para estes questionamentos é a de que a educação, quando ofertada com qualidade, torna-se condição necessária para que os sujeitos possam usufruir de outros direitos constituídos na sociedade democrática. E mais, é provável que uma educação de qualidade muito mais do que a instrução escolar, pode proporcionar um processo de modificação capaz de melhorar a visão de mundo, contribuindo para a formação de um senso crítico nestes sujeitos.

Para obter respostas possíveis a este questionamento, como método, foram realizadas entrevistas semiestruturadas com os agentes operadores do SGD governamentais e sociedade civil, a saber, Delegado da Delegacia de Proteção a Criança e ao Adolescente, Juiz da Vara da Infância e Juventude, Promo-

\footnotetext{
${ }^{6}$ Doutrina jurídica de controle do delito juvenil que não se dirige ao conjunto da população infanto-juvenil, mas apenas aos menores em situação irregular (carentes, abandonados, inadaptados e infratores). Nessa doutrina, além de se estabelecer as mesmas medidas para menores infratores e não infratores, além das medidas previstas em lei, o juiz pode aplicar outras que lhe pareçam convenientes. Neste sentido, o adolescente torna-se objeto de intervenção jurídica e social do Estado (Costa, 2006, p. 15-16).
} 
tor do Centro de Apoio Operacional de Educação, Defensor Público da Coordenadoria de Defesa dos Direitos da Criança e do Adolescente, Presidente do Conselho de Direitos da Criança do Adolescente, Diretor Geral e coordenações do Departamento de Ações Socioeducativas, Diretor da Diretoria Especial das Unidades Escolares Prisionais e Socioeducativas da Secretaria de Estado de Educação e Desembargador do Tribunal de Justiça do estado.

Para a análise de conteúdo das entrevistas, em linhas gerais, foram adotados procedimentos de transcrição das entrevistas, o agrupamento das respostas dos entrevistados de acordo com as respectivas perguntas e a criação de "eixos temáticos" a serem debatidos no estudo.

\section{Do controle estatal à Condição de Sujeito de Direitos}

Para a compreensão da Política Socioeducativa contemporânea, é necessário que recorramos ao histórico das políticas de atendimento a crianças e adolescentes no Brasil, onde é possível situar-se e perceber as permanências na atualidade de ideias e práticas que datam de mais de 100 anos de existência, mesmo quando o país faz a opção por uma moderna legislação de defesa dos direitos da infância e juventude.

Sob a égide da Doutrina da Situação Irregular, a infância e juventude pobres no Brasil eram tuteladas por políticas públicas que as consideravam "a margem” da sociedade. Crianças e adolescentes pobres ocupavam lugares estigmatizantes, marcados por preconceitos e ausência de reconhecimento desta fase da vida como um período específico de desenvolvimento que necessitava de atenção absoluta.

De acordo com Rizzini (2011), nesta configuração, o Estado atuando como interventor, elaborava políticas que demarcavam o lugar social que este público ocupava, marcado por faltas ou ausências, refletindo um processo histórico de subalternização e precariedade, o que gerou a necessidade de um aparato jurídico social de criminalização de crianças e adolescentes pobres.

Com promulgação dos chamados Código de Menores, a Doutrina da Situação Irregular é consolidada. Volpi (2001) nos ajuda a compreender que os Juizados de Menores, foi um instrumento importante, pois estabelecia uma relação prática jurídica. No entanto, apesar das contribuições, a forma como eram utilizados trouxeram relações desiguais marcadas por estigmas e exclusões.

O procedimento de institucionalização de crianças e adolescentes utilizava como fundamento científico padrões de normalidade baseados na medici- 
na psiquiátrica e na psicologia. Os cuidados com os "menores" tinham como objetivo controlar os desvios comportamentais ao ponto de trazê-los de volta à normalidade.

Contradições marcantes são visíveis entre os discursos protecionistas do chamado direito tutelar dos menores e as práticas assistencialistas e correcionais, pois na verdade estas legislações não foram criadas para proteger os "menores", mas sim, garantir a intervenção jurídica e moralista, preocupando-se com o conflito instalado e não com a prevenção. Eram destinadas a um grupo restrito, classificados, segundo Costa (2006), como abandonados, inadaptados e infratores, sendo o princípio básico desta doutrina, a judicialização das questões sociais e a institucionalização compulsória. Nas mãos do juiz, estava a tarefa de tutela, não sendo garantido nenhum direito, haja vista estes não serem considerados cidadãos.

Como forma de operacionalização desta doutrina, em meados do século XX, instituições de atendimento específicas para o atendimento a este público são edificadas e deixam grandes marcas em toda história. As centralizadas escolas correcionais, asilos, reformatórios, eram as responsáveis pelo sistema de reclusão equiparado ao dos adultos, para correção. $\mathrm{O}$ uso de métodos inadequados e repressivos, entenda-se violência, era o que mantinha o conceito de ordem e controle impresso pelo país.

Interessante se faz ressaltar que a história das instituições responsáveis pela privação de liberdade de crianças e adolescentes com objetivo de recolher, reprimir e educar se entrelaça com a história da assistência e da educação no Brasil. As instituições de atendimento ao adolescente infrator no país sempre tiveram o caráter de aprisionamento visto os exemplos de institucionalização do atendimento com o viés do isolamento, da retirada do convívio social daqueles a quem se atribua ou possa praticar atos infracionais.

O estado do Rio de Janeiro no contexto nacional, foi responsável por ter abrigado instituições de atendimento emblemáticas na sua história (Escola Correcional XV de Novembro em 1923, Escola João Luiz Alves ${ }^{8}$ em 1926, emtre outras).

\footnotetext{
Neste contexto, o termo menor é utilizado para designar a criança abandonada, desvalida, delinquente, viciosa, entre outras, e foi naturalmente incorporada na linguagem, para além do círculo jurídico (RIZZINI, 2011, p. 113). Optamos por dispor entre aspas a referida terminologia, por entender que encontra-se superada e ultrapassada de acordo com a legislação promulgada em 1990, sendo atualmente equivocada sua utilização.

${ }^{8}$ Esta unidade permanece nos dias atuais atendendo adolescentes do sexo masculino em cumprimento de medidas socioeducativas de privação de liberdade.
} 
Podemos compará-las ao que Goffman (2013) define como Instituição Total, em linhas gerais, um local de residência e trabalho, separados da sociedade mais ampla, levando uma vida fechada e formalmente administrada.

Como esclarece Liberati (2008, p. 62):

[...] funcionava [...] como um "sistema prisional", disfarçado de "internações" onde na verdade eram "penas de prisão" atendendo a máxima que a "privação total de liberdade" funcionaria como proteção da criança e adolescente influenciada pela sociedade e assim "obteriam um valioso resultado na reconstrução da personalidade.

As críticas ao sistema vigente começaram a emergir tanto por parte dos atores governamentais como da sociedade. Alguns juízes passaram a condenar estas instituições como fábrica de delinquentes, escolas do crime, lugares inadequados, desumano, ineficaz e perverso, concluindo ainda que esse estabelecimento tem contribuído para a formação de verdadeiros núcleos de criminosos, necessitando, assim, de outro modelo de atendimento a estes indivíduos (FALEIROS, 2011).

A partir da Nova Constituição Federal de 1946, de caráter liberal, movimentos sociais começam a surgir levantando assim, críticas aos modelos de justiça juvenil da época. Ainda assim, respondendo a uma demanda de um governo militar autoritário, é instituída a Fundação Nacional do Bem-Estar do Menor (FUNABEM) com o objetivo de enfrentar a questão da delinquência como um problema social e de Segurança Nacional, além de objeto legítimo de intervenção e normatização.

No cenário internacional, os equívocos vivenciados no trato com crianças e adolescentes no que se refere aos direitos a eles destinados, são pauta das agendas dos principais organismos internacionais de defesa deste público. A configuração política do período (pós-guerra mundial), necessitava de reformulações que caminhassem a favor dos Direitos Humanos. Neste sentido, em 1948, a Organização das Nações Unidas (ONU) aprova a Declaração Universal dos Direitos do Homem.

Com a aprovação da Convenção sobre os direitos das crianças, que ratifica a Declaração, um novo olhar passa a ser destinado sobre este público reconhecendo-lhes normas e medidas de proteção que todos os países signatários devem adotar. Sendo o Brasil um dos adeptos. 
Os tratados internacionais ${ }^{9}$ traziam consigo princípios básicos que deveriam refletir um conjunto de regras a fim de proteger os direitos fundamentais deste público em questão. Tais documentos demonstram a concepção de uma evolução sociojurídica internacional que visam garantir direitos as crianças e adolescentes em situação de restrição e privação de liberdade.

Aproximando-se da década de 1980, visto a crise e o esgotamento do modelo gestor vigente, seguindo princípios e tendências internacionais, o Brasil clamava por um regime político democrático que atendesse aos anseios da população pela consolidação de um Estado de direito.

O cenário brasileiro da decadência das práticas de caridade e privatização das políticas públicas, faz emergir na constituição do país - assim como em grande parte dos países da América Latina - elementos fundamentais para sua organização: movimentos sociais, políticas públicas e mundo jurídico (MENDEZ, 1994).

Organizações não governamentais de defesa dos direitos das crianças e dos adolescentes, influentes no projeto da Convenção dos Direitos da Criança da ONU, iniciaram um movimento em direção a cobrança por introdução do conteúdo dos documentos das Nações Unidas na Constituição Federativa do Brasil.

A Constituição de 1988 significou um grande avanço nos direitos sociais e isto, por sua vez, beneficiou a criança e o adolescente. Com o avanço da abertura política no Brasil, vozes surgiram de diferentes segmentos para denunciar as injustiças e as atrocidades que eram cometidas contra as crianças e adolescentes no país, mostrando que crianças pobres não tinham sequer direito à infância.

Muitos movimentos questionavam o tratamento dado às crianças em "situação irregular" e as indiscriminadas internações determinadas pelos Juizados de Menores. A visibilidade crescente dos meninos de rua nos anos 1980, quando da falência da FUNABEM, também impulsionaram a articulação de vários grupos em defesa dos seus direitos.

Com esta carta constitucional, o Brasil rompe no campo legal com a Situação Irregular e adere integralmente a Doutrina da Proteção Integral quando reconhece crianças e adolescentes como sujeitos de direitos atribuindo-lhes prioridade absoluta e responsabilizando os entes, família, estado e sociedade por sua proteção, além de considerá-los como pessoa em condição peculiar de desenvolvimento, previstas em seu artigo 227.

\footnotetext{
${ }^{9}$ Regras de Beijing, Diretrizes de Riaad, Regras Mínimas das Nações Unidas para proteção dos jovens privados de liberdade.
} 
Baseado nos princípios constantes neste artigo, em 1990 foi sancionada a Lei 8.069, o Estatuto da Criança e Adolescente, popularmente conhecido como "ECA". Este avanço, no campo legal, representa a mudança de paradigma no trato da infância e adolescência, agora não mais restringindo a um grupo específico, e sim atingindo a toda população compreendida na faixa etária de 0 a 18 anos.

Esta lei consagra também a concepção de funcionamento através do Sistema de Garantia de Direitos, onde são previstos órgãos especializados de administração e execução de toda política de atendimento.

Como interesse deste estudo, as atenções estarão concentradas no atendimento socioeducativo que aborda a responsabilização penal do adolescente através das medidas socioeducativas previstas no artigo 112 da lei.

\section{Política Socioeducativa: Sua organização e seus fins}

O ECA representa seguramente um novo panorama para o atendimento socioeducativo. Tal afirmativa é baseada na concepção de sua compreensão do adolescente autor de ato infracional também como sujeito de direitos de garantias, e preconiza que em toda condução de atendimento, este deve ser com cunho educativo.

Para tal, são instituídas as medidas socioeducativas que são, na verdade, uma resposta sancionatória do Estado, só que por se tratar do público em questão, comportam, além deste aspecto jurídico, a natureza ética e pedagógica, de modo a contribuir com seu desenvolvimento pessoal e social, levando-os a reconhecer e reparar o erro cometido. Sendo seu maior desafio, a prevalência nos aspectos educativos sobre os punitivos.

As medidas socioeducativas são: I- advertência; II- obrigação de reparar o dano; III- prestação de serviços à comunidade; IV- liberdade assistida; V- inserção em regime de semiliberdade; VI- internação em estabelecimento educacional; VII- além de qualquer uma das medidas de proteção previstas no art.101, I a VI.

No Rio de Janeiro, estas medidas são executadas pelo Departamento Geral de Ações Socioeducativas - Degase (Internação e Semiliberdade) e pela Secretaria de Estado e Assistência Social - SEASDH (Prestação de Serviços a comunidade e Liberdade Assistida).

De forma a operacionalizar a política, o ECA como instrumento normatizador, apresenta a inovação de ações descentralizadas no âmbito do poder 
público, com atribuições e responsabilizações aos entes federais, estaduais e municipais. A política nacional integrada aos sistemas estaduais, municipais e distrito federal é quem normatiza e articula a política socioeducativa.

Como forma de executar as medidas socioeducativas e ratificar o ECA, em 2012 é sancionado o Sistema Nacional de Atendimento Socioeducativo SINASE, que agora passa a ser considerada mais uma política pública para juventude, só que com um diferencial, ela é específica para um determinado grupo, com duração e lugares limitados.

O SINASE, neste contexto, passa a articular as políticas setoriais (saúde, educação, justiça, etc.) que compõe o SGD, visto sua função de articular e integrar instâncias públicas governamentais e da sociedade civil na aplicação de instrumentos normativos e no funcionamento dos mecanismos de promoção, defesa e controle para a efetivação dos direitos da criança e do adolescente nos níveis Federal, Estadual, Distrital e Municipal e nos poderes Executivo, Legislativo e Judiciário

Assim como o ECA, esta Lei vem sendo considerada como avanço, pelo menos no plano normativo, para o Estado brasileiro que passa a contar com um mecanismo legal que prevê a efetiva execução das medidas, pois passa a compreender o adolescente não mais como problema e sim como prioridade social do país. Neste sentido, o SINASE propõe uma reformulação tanto na estrutura física das unidades socioeducativas responsáveis pela execução das medidas, quanto a natureza e qualidade do atendimento, estabelecendo as diretrizes para as áreas jurídicas, financeiras, administrativa, saúde, assistência social, educação, profissionalização e segurança, tornando seus representantes corresponsáveis em todo processo.

Infelizmente, apesar do avanço no campo da legislação, e em especial da Lei SINASE, a dimensão prática do atendimento ainda demonstra sinais de insuficiência e ineficácia. A mudança de normativa requer então uma mudança abrupta tanto nos aspectos físicos quanto humanos no que se refere a compreensão dos fins da socioeducação ${ }^{10}$. Além de um compromisso público no que se refere aos investimentos e financiamentos.

\footnotetext{
${ }^{10}$ De acordo com Costa (2006, p. 10) "ação educativa destinada a preparar os adolescentes para o convívio social no marco da legalidade e da moralidade socialmente aceitas, como forma de assegurar sua efetiva e plena socialização."
} 


\section{Concepção da Socioeducação}

O Sistema socioeducativo, através das políticas para área nas últimas décadas, vem tentando romper com paradigmas históricos visando reafirmar e consolidar a natureza pedagógica que deve permear suas ações. Ao afirmar seu caráter jurídico pedagógico, tem-se o entendimento de que a política socioeducativa deve ser diferente da Lei de Execuções Penais - LEP destinada aos adultos, que possui como grandes objetivos, resumidamente, a proteção da sociedade (entenda-se pessoas e seu patrimônio) do indivíduo que cometeu o crime, a punição e a ressocialização, sendo a incidência de aspectos pedagógicos no cumprimento da pena, um dos caminhos, e não o relevante.

Entretanto, o que encontramos no cenário atual, são concepções de que o caráter das medidas, assim como a pena, é somente de punir o indivíduo pelo ato infracional cometido como forma de regulação da sociedade, o que contraria toda perspectiva já abordada neste estudo.

Um dos objetivos da socioeducação é construir junto aos adolescentes, novos e apropriados conceitos de vida, buscando o fortalecimento dos princípios éticos da vida social. Neste sentido, entendemos que o trabalho socioeducativo requer uma Pedagogia voltada para formação da pessoa e do cidadão que promova a formação e desenvolvimento do sentido da responsabilidade do sujeito para consigo mesmo e para com os outros.

A Pedagogia Social neste contexto, seria a de fazer com que os processos educativos latentes na sociedade educadora sejam "intencionalmente" orientados, aconteça onde acontecer: na escola, na família, no abrigo, nos meios de comunicação, nas instituições (CALIMAN, 2010). Seu conteúdo e objeto é a Educação Social, que pode ser entendida como as ações e projetos de intervenção pedagógica promotores da qualidade de vida em sociedade.

A socioeducação, por se tratar de uma política que possui um componente específico e peculiar, requer desta forma a criação de oportunidades e condições educativas que favoreçam o desenvolvimento pessoal e social do adolescente, criando acontecimentos estruturantes que possibilitem a viabilização deste enquanto pessoa, ajudando-o a desenvolver sua autonomia.

Ao afirmar que no atendimento socioeducativo a Educação é parte estruturante, tendo em vista o conteúdo educativo que deve permear suas ações, esta modalidade adquire enorme relevância nesta temática. A condição de privação ou restrição de liberdade faz com que se compreenda que as práticas educativas não se dão somente em ambientes tradicionais como a escola, abrangendo 
também os contextos comunitários e institucionais que desenvolvem formas de educação igualmente significativas e influentes, sendo por esta afirmativa, a Pedagogia Social através da Educação Social, que sustenta a concepção de Socioeducação.

O conceito de Socioeducação definido pelo governo através da exSecretaria de Direitos Humanos da Presidência da República - SDH/PR ao qual apresentava como diretriz para gestão e execução da ação socioeducativa, baseava-se nas ideias de Antonio Carlos Gomes da Costa, que a define como educação para socialização (COSTA, 2006) e promovendo o caminho do desenvolvimento pessoal e social, ou seja, preparar o indivíduo para avaliar soluções e tomar decisões corretas em cima de valores, aprender a ser e a conviver.

Acreditando que toda intervenção social necessita ter o paradigma educativo, espera-se que a compreensão do caráter pedagógico das ações socioeducativas possibilite aos adolescentes condições de construir um modo de viver que lhes permita o exercício de sua liberdade com responsabilidade, ou seja, vivenciar práticas educativas que promovam a socialização e, consequentemente, formação para cidadania, com novas competências pessoais e relacionais para suas vidas.

Nas prerrogativas da Educação Social e, consequentemente, na Socioeducação ${ }^{11}$, a educação deve contribuir para o desenvolvimento total da pessoa espírito e corpo, inteligência, sensibilidade, sentido estético, responsabilidade pessoal, espiritualidade, ou seja, em sua totalidade para suas relações.

Nesta direção, entendemos que a educação na socioeducação necessita ser percebida como o processo que transforma o potencial das pessoas em competências, capacidades e habilidades, necessitando ser crítica, diretiva e democrática. Sendo através da ação educativa que seu potencial é desenvolvido, promovendo, assim, sua convivência social.

$\mathrm{O}$ adolescente que cometeu ato infracional e em situação de cumprimento de medida socioeducativa não perdeu sua natureza de ser em desenvolvimento e sujeito de direitos. A representação social que se tem do adolescente infrator impõe-lhe uma repressão social que não reconheça neste um ser a quem ações podem transformar sua condição social. Ou seja, dirigir intervenções pedagógicas que promovam o crescimento moral, cognitivo, social, espiritual e psicológico, considerando sempre que seu desenvolvimento deve se dar dentro de uma visão holística, principalmente reconhecendo que ele é um sujeito que está em fase de desenvolvimento.

11 No que se refere a Educação Social tratada neste estudo, quando tratado termo "Socioeducação", o mesmo está relacionado a Educação no Sistema Socioeducativo. 
A concepção da ação educativa no atendimento, sem sombra de dúvida, representa um avanço considerável no sentido de superar antigos paradigmas. O caráter eminentemente pedagógico sobre o punitivo aponta para o sentido prospectivo do adolescente em conflito com a lei, configurando-se como uma ação política.

Paradoxalmente, frente ao cenário atual, é perceptível que apesar das legislações e concepções acerca do Sistema Socioeducativo, qualquer diagnostico sobre o mesmo, que inclui não só as unidades executoras, mas também os órgãos que compõe o SGD, revela o descumprimento dessa lei. Ou seja, como afirma Passeti (1999), a promulgação de uma lei não é o suficiente para mudar os rumos da história, e será ineficaz se não estiver legitimada socialmente.

\section{Considerações Finais}

Mediante ao material coletado nas entrevistas, é possível entender que o que hoje conhecemos por medida socioeducativa nem sempre existiu. Se, em um passado recente, no Brasil a medida socioeducativa já teve natureza eminentemente repressora, hoje a mesma possui expressamente conteúdo ético-pedagógico, assegurado pela legalidade que, em tese, assegura a prática de ações educativas de maneira que promovam nestes adolescentes, meios para lhes educar para a vida em liberdade.

As discussões neste campo só são incorporadas nas agendas políticas em razão da luta dos movimentos sociais quando da elaboração da Constituição Federal vigente e tratados internacionais.

Ao longo deste estudo, percebemos claramente que o presente ainda é marcado por um passado de ações violadoras, porém com um diferencial. No contexto atual, as legislações e os referenciais teóricos dos Sistemas de Atendimento apregoam concepções que viabilizem a estes sujeitos, experiências através de ações educativas que os potencializem e transformem.

Sendo assim, ideias de transformação, autonomia e cidadania passam a integrar os objetivos das respostas dos poderes públicos aos atos infracionais. Um avanço é claro! Ter garantido em instrumentos legais tais prerrogativas, tende a gerar uma responsabilização maior de quem é responsável por tais ações, neste caso, todo o Sistema de Garantia de Direitos.

No entanto, podemos avaliar que o sistema socioeducativo tem se caracterizado historicamente pela precariedade de suas ações. No cenário atual, é possível perceber a omissão de direitos ao público destinatário desta política, 
referendando-se às práticas que revelam o grande hiato entre o direito assegurado na lei e o que de fato acontece no cotidiano de sua execução.

O desrespeito e o descumprimento à lei pelo despreparo do Estado em assumir de fato a concepção, não tem deixado perceber o caminho para o redirecionamento social tanto dos adolescentes, assim como da segurança para toda população, sendo notadamente percebida a pouca importância dada a esta temática.

Os agentes do SGD reconhecem o caráter educativo de toda ação socioeducativa, entretanto, a forma de operacionalizar esta prerrogativa ainda encontra dificuldades, principalmente em sua compreensão no que se refere as ações cotidianas educativas. O entendimento maior está relacionado ao seu fim, a ressocialização, e não ao processo.

No estado do Rio de Janeiro, assim como no Brasil, os processos que envolvem a implementação da política de atendimento socioeducativo têm sido lentos e marcados por práticas inconstantes e arbitrárias por parte de seus operadores. Esta característica reforça ainda mais a ideia de que princípios e objetivos constitucionais por si só não modificam a realidade, que, neste caso, é herdeira de práticas de violações e omissões que apenas ajustavam estes adolescentes ao mundo sem a intenção de integrá-los.

Um dos grandes paradoxos que se revelaram, refere-se também a política de execução do estado do Rio de Janeiro, que vive um intenso momento de transformações e adequações, com autonomia financeira e descentralização administrativa. O Degase hoje inclusive pioneiramente integra a estrutura do organograma da Secretaria de Estado de Educação.

No Rio de Janeiro também é possível encontrar um Sistema de Garantia de Direitos estruturalmente consolidado, ou seja, com a presença das instituições responsáveis pela proteção e garantia conforme previsto no SINASE. Por outro lado, as constantes ausências de ações articuladas fazem com que o mesmo apresente fragilidades em sua operacionalização no Sistema Socioeducativo.

Conforme evidenciado na pesquisa, cada ente do SGD atua de forma isolada, o que não corresponde ao preconizado. Vale aqui reafirmar que, como compreendido neste estudo, o sucesso da ação socioeducativa não depende somente de um agente do Sistema. Sendo assim, fica perceptível que esta fragilidade é decorrente também da ausência de ações articuladas, onde os demais agentes assumam suas responsabilidades frente ao compromisso da Socioeducação. 
Somente conhecer o SINASE, não significa por si só avançar para uma ação socioeducativa sob novas bases. Como observamos na pesquisa, a lógica da Política Socioeducativa estadual se mantém no nível micro, ou seja, sob a lógica da "adaptação". Pegar o novo e adaptar sobre o velho, não rompendo definitivamente com este.

A construção de um novo modelo implica a desconstrução, sempre resistida, de velhos olhares e velhas práticas cristalizadas que teimam em perpetuar-se. No caso do Rio de Janeiro, que serviu de palco para a execução das políticas anteriores ao ECA, percebemos que apesar dos avanços materiais, não superou, seja na gestão e execução, formas "menorista" de atendimento.

Precisamos realmente avançar na implementação de políticas que respeitem o previsto na nossa legislação. Que as ações políticas realmente levem em consideração práticas socioeducativas que garantam sob qualquer coisa, o direito do sujeito em cumprimento de medida socioeducativa.

\section{Referências}

BRASIL. Constituição (1988). Constituição da República Federativa do Brasil. Brasília, DF: Congresso Nacional, 1988.

Lei $\mathbf{n}^{\circ}$ 8.069, de 1990. Estatuto da Criança e do Adolescente. Diário Oficial da União - Seção 1 - 16/7/1990, Página 13563 (Publicação Original), Brasília, DF, 1990.

Lei $\mathrm{n}^{\circ}$ 12.594, de 2012. Sistema Nacional de Atendimento Socioeducativo. Diário Oficial da União - Seção 1 - 19/1/2012, Página 3 (Publicação Original). Brasília, DF, 2012.

CALIMAN, G. Pedagogia Social: seu potencial crítico e transformador. Revista de Ciências da Educação, Americana, ano XII, n. 23, p. 341-368, 2010.

COSTA, Antônio Carlos Gomes da. Socioeducação: Estrutura e Funcionamento da Comunidade Educativa. Brasília: Secretaria Especial de Direitos Humanos, 2006a.

. Por uma Política Nacional de Execução das Medidas Socioeducativas: Princípios Norteadores. Brasília: Secretaria Especial de Direitos Humanos, 2006b. 
Parâmetros para a Formação do Socioeducador: uma proposta inicial para Reflexão e Debate. Brasília: Secretaria Especial de Direitos Humanos, 2006c.

Os Regimes de Atendimento no Estatuto da Criança e do Adolescente: Perspectivas e Desafios. Brasília: Secretaria Especial de Direitos Humanos, 2006d.

As Bases Éticas da Ação Socioeducativa: Referenciais Normativos

e princípios Norteadores. Brasília: Secretaria Especial de Direitos Humanos, 2006e.

FALEIROS, V. de P. Infância e processo político no Brasil. In: RIZZINI, I.; PILOTTI, F. (orgs). A arte de governar crianças: a história das Políticas Sociais, da legislação e da assistência à infância no Brasil. 3. ed. São Paulo: Cortez, 2011. p. 33-96.

GOFFMAN, E. Manicômios, Prisões e Conventos. 8. ed. São Paulo: Perspectiva, 2013.

LIBERATI, W. D. Comentários ao estatuto da criança e do adolescente. 10. ed. São Paulo: Malheiros Editores, 2008.

MENDEZ, Emílio Garcia. COSTA, Antônio Carlos Gomes da. Das necessidades aos Direitos. Série Direitos da Criança 4. São Paulo: Malheiros, 1994.

NOGUEIRA, Wanderlino N. Comentários ao artigo 234 do ECA, em Cury, Munir Silva et al. Coords: Estatuto da Criança e do Adolescente comentado Comentários jurídicos e sociais, 2.ed, São Paulo: Malheiros, 1996.

PASSETI, Edson. Crianças carentes e políticas públicas. In: História das crianças no Brasil. São Paulo: Contexto, 1999.

RIZZINI, I. (org). A arte de governar crianças: a história das Políticas Sociais, da legislação e da assistência à infância no Brasil. 3. ed. São Paulo: Cortez, 2011.

VOLPI, M. (org). Sem Liberdade, sem direitos: a Privação de liberdade na percepção do Adolescente. São Paulo: Cortez, 2001. 
